\title{
PROGRESSIVE COLLAPSE ANALYSIS OF AN RC STRUCTURE SUBJECTED TO SEISMIC LOADS IN SLOPING GROUND
}

\author{
Shilpa Shree G C 1 , Syed Ahamed Raza ${ }^{2}$ \\ ${ }^{1}$ Post Graduate student, Ghousia college of engineering, Ramnagaram \\ ${ }^{2}$ Assistant professor, Ghousia college of engineering, Ramnaram
}

\begin{abstract}
Progressive Collapse is the spread of initial failure from element to element leading to entire collapse of an structure. It is due to vehicle impacts, fire,earthquakes and natural or man made hazards. Collapse leads to large proprtions of dispropriate triggers in the structures which makes structures incapable of withstanding loads and it leads to collapse of the structure. In this study special moment resisting frame of G+19 story building is modeled using FEM based software( ETABSV9.7). The analysis is carried as per GSA gudelines in zone V having medium soil by linear dynamic and non linear analysis. The story drift and story shears are calculated to know the potential for progressive collapse of an structure.
\end{abstract}

Keywords: Progressive Collapse,Column Removal ,Dynamic Analysis, Push Over Analysis etc... - ***

\section{INTRODUCTION}

Progressive collapse is "the spread of an initial local failure from element to element, eventually resulting in the collapse of an entire structure or a disproportionately large part of it." In this collapse mechanism a single deformation may lead to entire collapse in the structure, it can be inferred that progressive collapse is triggered more due to the sudden removal of column than the collapse of a structure due to earth quake loads.

Once a column is removed or made weak, due to man-made or natural hazards, load carried by column removed is transferred to neighbouring columns in the structure, if the neighbouring column is incapable of withstanding the extra load, leads to the progressive failure of adjoining members and finally to the failure of partial or whole structure. The collapsing system continually seeks alternative load paths in order to survive.

\subsection{General}

Stability of a slope can be affected by seismicity in two ways: earthquake and blasting. These seismic motions are capable of inducing large destabilizing inertial forces. In general, three methods of analysis have been proposed for the evaluation of slopes response under such conditions.

1 Pseudostatic Method: The earthquake's inertial forces are simulated by the inclusion of static horizontal and vertical forces in limit equilibrium analysis.

2. Newmark's Displacement Method: This method is based on the concept that the actual slope accelerations may exceed the static yield acceleration at the expense of generating permanent displacements.

3. Dynamic Finite Element Analysis: This is a coupled two or three dimensional analyses using appropriate constitutive material model that will provide details of concerning stresses, strains, and permanent displacement.

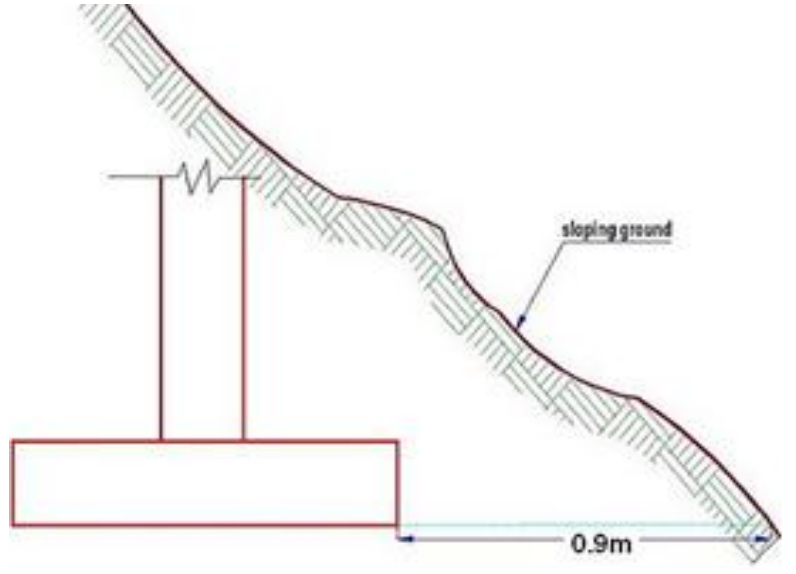

Fig 1 shows the sloping ground

\subsection{Progressive Collapse Mechanism}

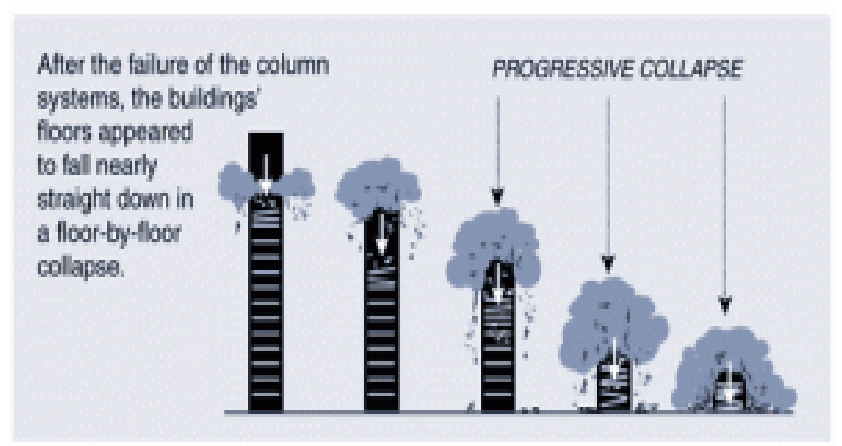

Fig 2 shows the mechanism of progressive collapse

Progressive Collapse is "the collapse of multiple bays or floors of a structure resulting from an isolated structural failure due to a chain reaction or domino effect". Any extreme loading that damages structural components such as support beams and columns are subjected to potential cause for progressive collapse. The mechanics of Progressive Collapse has two phases: "Crush-down, whereby gravity 
and the immense downward kinetic thrust of floors upon mashed floors successively crushes everything below, gives way to crush-up, the free-falling top floors now piling on top of the wreckage. This second phase further pulverizes the rubble". The nature of the Progressive Collapse which contains impulsive and dynamic external loads make it difficult to fully predict its random occurrence.

\subsection{GSA Guidelines}

The General Service Administration (GSA) analysis includes removal of one column at a time from the story 1 above the ground floor. GSA provides criteria for column removal for static analysis case. According to that a column is removed as mentioned below for typical structures.

- Exterior Column in the middle of longer side of building.

- Exterior column in the middle of shorter side of the building.

- Corner column.

\subsection{Objectives}

The objectives of this present study is to:

- To find the capacity of the building using capacity spectrum method.

- To compare various results such as story shear and story drift for bare frame model and model with removal of column in the different stories.

- To evaluate the potential for progressive collapse of a twenty story symmetrical reinforced concrete building using the dynamic analysis and push over analysis for column removal conditions.

- To find the elastic behavior of the building by plotting push over curve.

\subsection{Methods of Analysis}

* Linear dynamic ( Response spectrum) analysis

* Non linear static analysis

\section{Non Linear Analysis}

Nonlinear static analysis procedure is carried out in the following steps using ETABV9.7 Software.

- Build a finite-element computer model.

- Define and assign nonlinear plastic hinge properties, to beams and columns.

- Apply static load combination.

- Perform nonlinear static analysis

- Verify and validate the results based on hinge formation.

\section{MODEL DESCRIPTION}

Table 1: Model description

\begin{tabular}{|l|l|}
\hline STRUCTURE TYPE & SMRF \\
\hline SEISMIC ZONE & $\mathrm{V}$ \\
\hline FLOOR HEIGHT & $3.2 \mathrm{~m}$ \\
\hline LIVE LOAD & $3 \mathrm{kn} / \mathrm{m}$ \\
\hline MATERIALS & Concrete(M30)\&Steel(FE \\
\hline
\end{tabular}

\begin{tabular}{|l|l|}
\hline & $415)$ \\
\hline PLAN DIMENSION & $20 \mathrm{mX24m}$ \\
\hline $\begin{array}{l}\text { NO. OF BAY IN X } \\
\text { DIRECTION }\end{array}$ & 5 \\
\hline $\begin{array}{l}\text { NO, OF BAY IN Y } \\
\text { DIRECTION }\end{array}$ & 8 \\
\hline SIZE OF COLUMN & $0.35 \mathrm{mx0.8m}$ \\
\hline SIZE OF BEAM & $0.25 \mathrm{mx} 0.4 \mathrm{~m}$ \\
\hline SLAB THICKNESS & $0.12 \mathrm{~m}$ \\
\hline SOIL TYPE & II \\
\hline $\begin{array}{l}\text { IMPORTANCE } \\
\text { FACTOR, I }\end{array}$ & 1.5 \\
\hline $\begin{array}{l}\text { RESPONSE } \\
\text { REDUCTION } \\
\text { FACTOR, R }\end{array}$ & 5 \\
\hline
\end{tabular}

The following exterior analysis cases should be considered. 1.Analyze for the bare frame model of the building

2. Analyze for the removal of a column above 5th storey located at corner of the short side of the building (C41).

3. Analyze for the removal of a column above 5th storey located at middle of the short side of the building (C31).

4 Analyze for the removal of a column above 1 st storey located at the middle of the longer side of the building (C37).

5.Analyze for the removal of a column above 1st storey) located at the middle of the long side of the building (C43).

A separate analysis must be performed for each case. While performing a static linear analysis, the vertical load case applied to the structure is as

$$
\text { Load }=1.5(\mathrm{DL}+\mathrm{LL})
$$

Where, DL = Dead Load, and LL = Live Load.

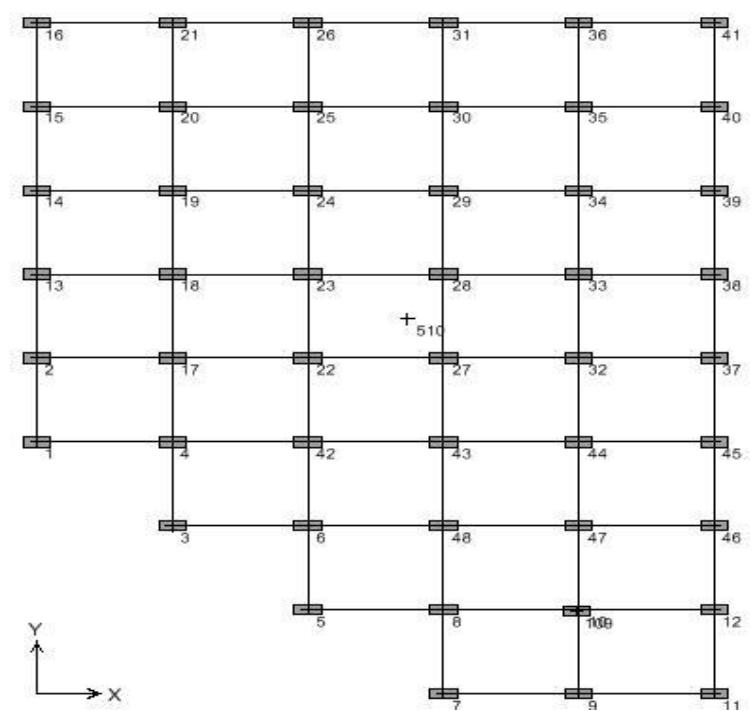

Fig 3 shows the plan of the bare frame model 


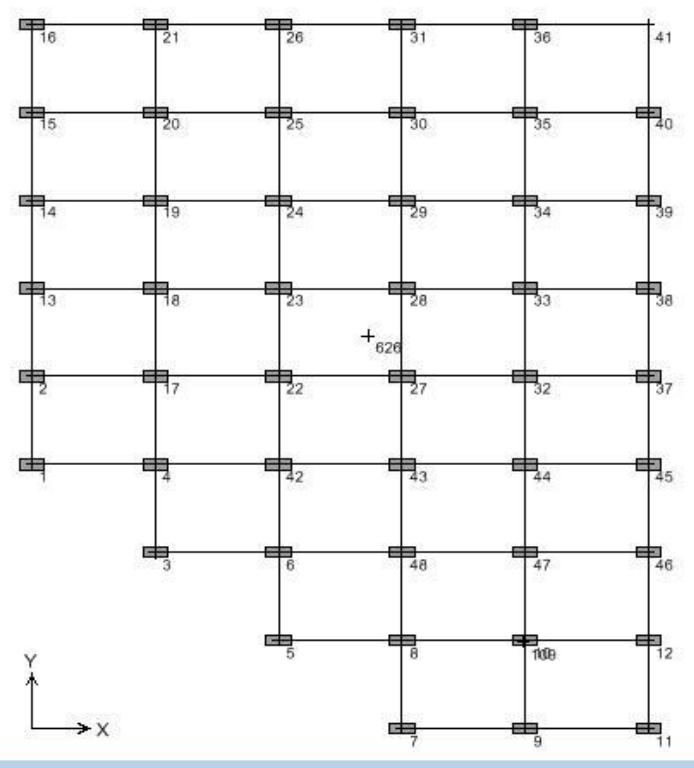

Fig 4 shows the plan of removal of corner column in the shorter direction (C41).

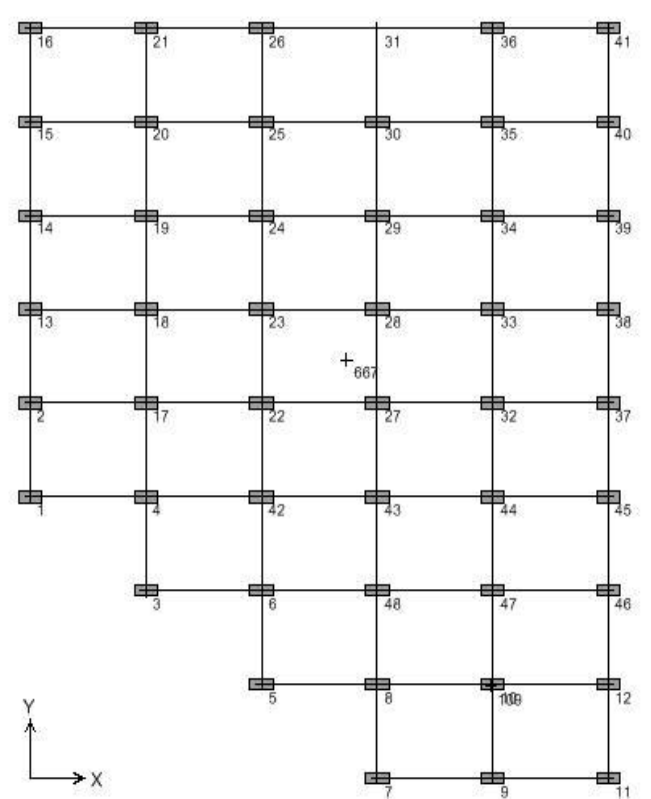

Fig 5 shows the plan of removal of middle column in the shorter direction (C31).

\section{RESULTS}

\subsection{Bare Frame Results}

Table 2 : story drift of bare frame model

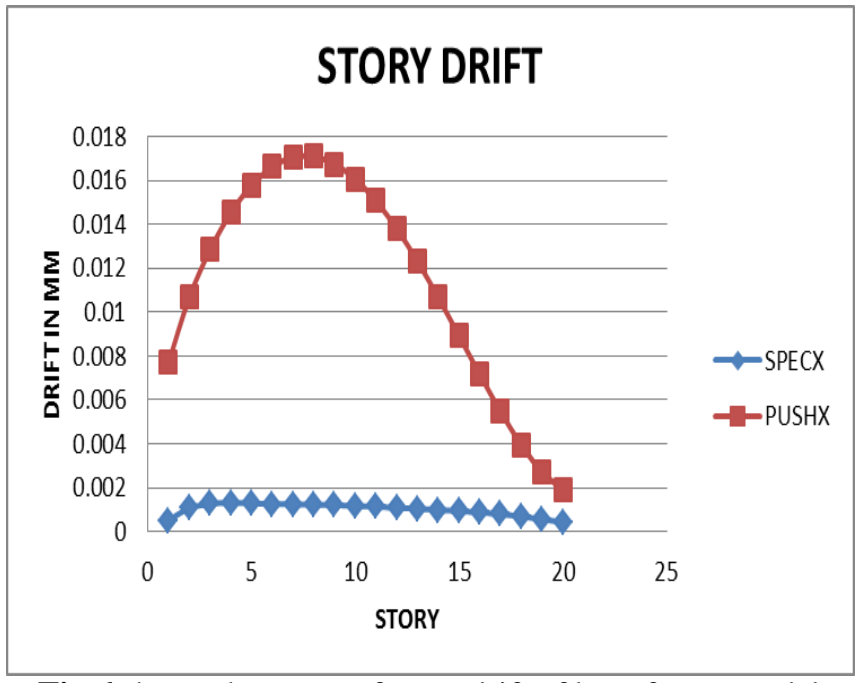

Fig 6 shows the curve of story drift of bare frame model

Table 3 : story shear of bare frame model

\begin{tabular}{|c|c|c|}
\hline STORY & SPECX & PUSHX \\
\hline 20 & 202.42 & 315.13 \\
\hline 19 & 406.45 & 663.2 \\
\hline 18 & 560.66 & 975.71 \\
\hline 17 & 667.64 & 1254.59 \\
\hline 16 & 740.12 & 1501.74 \\
\hline 15 & 795.01 & 1719.08 \\
\hline 14 & 844.69 & 1908.53 \\
\hline 13 & 892.23 & 2072.01 \\
\hline 12 & 939.81 & 2211.41 \\
\hline 11 & 983.97 & 2328.67 \\
\hline 10 & 1026.59 & 2425.7 \\
\hline 9 & 1067.83 & 2504.4 \\
\hline 8 & 1106.88 & 2566.71 \\
\hline 7 & 1144.81 & 2614.52 \\
\hline 6 & 1186.69 & 2649.72 \\
\hline 5 & 1238.24 & 2674.3 \\
\hline 4 & 1297.99 & 2690.14 \\
\hline 3 & 1354.99 & 2699.14 \\
\hline 2 & 1394.7 & 2703.23 \\
\hline 1 & 1410.04 & 2704.33 \\
\hline
\end{tabular}

Error! Not a valid link. 


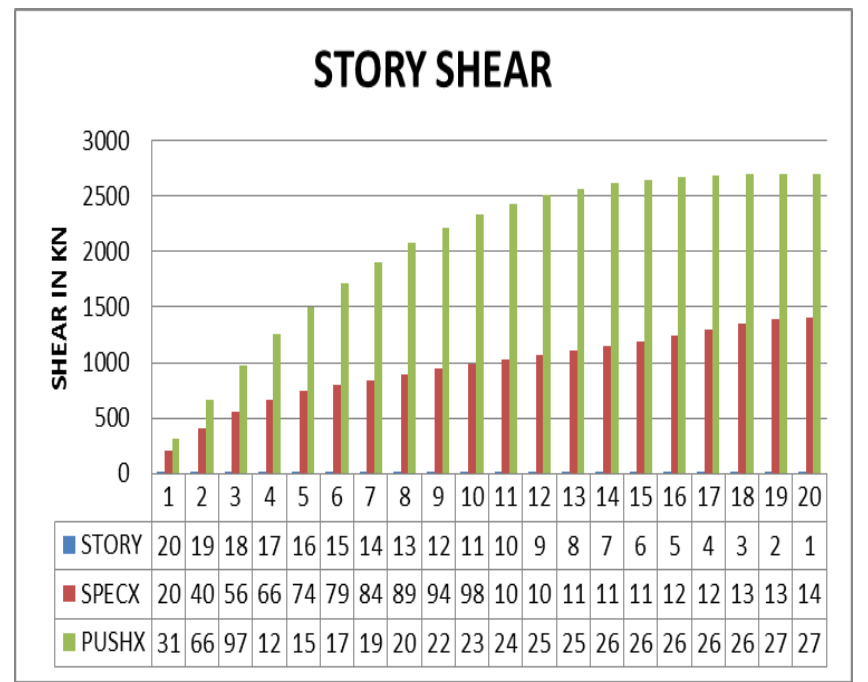

Fig 7 shows the curve for story shear of bare frame model

3.1.1 Results of Removal of Corner Column in Shorter Direction

\section{Story Drift}

Table 4 : story drift of removal of corner column in shorter direction

\begin{tabular}{|l|l|l|}
\hline STORY & SPECX & PUSHX \\
\hline 20 & 0.000228 & 0.00181 \\
\hline 19 & 0.000296 & 0.002594 \\
\hline 18 & 0.000367 & 0.003787 \\
\hline 17 & 0.000425 & 0.005258 \\
\hline 16 & 0.000469 & 0.006896 \\
\hline 15 & 0.000502 & 0.008603 \\
\hline 14 & 0.000528 & 0.010294 \\
\hline 13 & 0.00055 & 0.011893 \\
\hline 12 & 0.000568 & 0.13333 \\
\hline 11 & 0.000584 & 0.014557 \\
\hline 10 & 0.000599 & 0.015515 \\
\hline 9 & 0.00613 & 0.016165 \\
\hline 8 & 0.000626 & 0.016471 \\
\hline 7 & 0.0000633 & 0.016403 \\
\hline 6 & 0.000636 & 0.0159 \\
\hline 5 & 0.000664 & 0.015025 \\
\hline 4 & 0.000678 & 0.013757 \\
\hline 3 & 0.000653 & 0.01206 \\
\hline 2 & 0.000549 & 0.009896 \\
\hline 1 & 0.000266 & 0.00696 \\
\hline & &
\end{tabular}

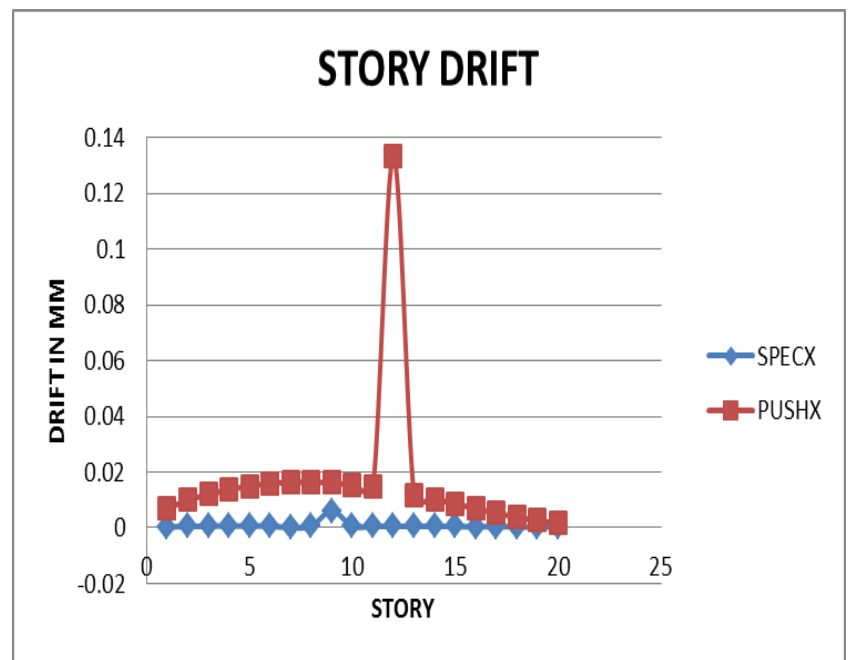

Fig 8 shows curve for story drift of removal of corner column in shorter direction

\section{Story Shear}

Table 5 : story shear of removal of corner column in shorter direction

\begin{tabular}{|l|l|l|}
\hline STORY & SPECX & PUSHX \\
\hline 20 & 108.31 & 311.67 \\
\hline 19 & 218.96 & 657.3 \\
\hline 18 & 303.99 & 967.63 \\
\hline 17 & 364.32 & 1244.55 \\
\hline 16 & 405.67 & 1489.97 \\
\hline 15 & 435.62 & 1705.79 \\
\hline 14 & 459.79 & 1893.91 \\
\hline 13 & 480.39 & 2056.24 \\
\hline 12 & 498.04 & 2194.67 \\
\hline 11 & 514.04 & 2311.11 \\
\hline 10 & 530.48 & 2407.45 \\
\hline 9 & 548.74 & 2485.61 \\
\hline 8 & 568.85 & 2547.47 \\
\hline 7 & 591.01 & 2594.84 \\
\hline 6 & 616.81 & 2629.82 \\
\hline 5 & 647.98 & 2654.16 \\
\hline 4 & 682.77 & 2669.88 \\
\hline 3 & 714.89 & 2678.82 \\
\hline 2 & 736.83 & 2682.88 \\
\hline 1 & 745.2 & 2683.97 \\
\hline
\end{tabular}




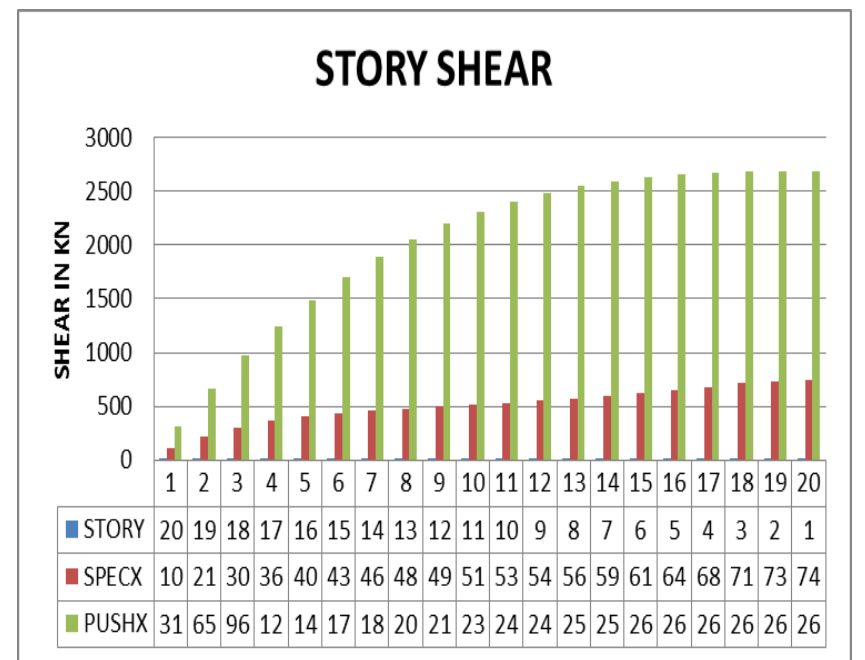

Fig 9 shows the curve of story shear of removal of corner column in shorter direction.

3.1.2 Results of Removal of Middle Column in Shorter Direction

\section{Story Drift}

Table 6 : story drift of removal of middle column in shorter

\begin{tabular}{|l|l|l|}
\hline \multicolumn{3}{|c}{ direction } \\
\hline 20 & 0.000309 & 0.001862 \\
\hline 19 & 0.000401 & 0.002666 \\
\hline 18 & 0.000502 & 0.00389 \\
\hline 17 & 0.000591 & 0.005403 \\
\hline 16 & 0.000663 & 0.00709 \\
\hline 15 & 0.000723 & 0.008849 \\
\hline 14 & 0.000772 & 0.010592 \\
\hline 13 & 0.000814 & 0.012245 \\
\hline 12 & 0.00085 & 0.01374 \\
\hline 11 & 0.000882 & 0.015018 \\
\hline 10 & 0.000911 & 0.01603 \\
\hline 9 & 0.000939 & 0.016737 \\
\hline 8 & 0.000962 & 0.017106 \\
\hline 7 & 0.000976 & 0.017111 \\
\hline 6 & 0.00098 & 0.016708 \\
\hline 5 & 0.001039 & 0.015897 \\
\hline 4 & 0.001038 & 0.014602 \\
\hline 3 & 0.00099 & 0.012975 \\
\hline 2 & 0.000829 & 0.010887 \\
\hline 1 & 0.000409 & 0.008106 \\
\hline & & \\
\hline & & \\
\hline 1 & &
\end{tabular}

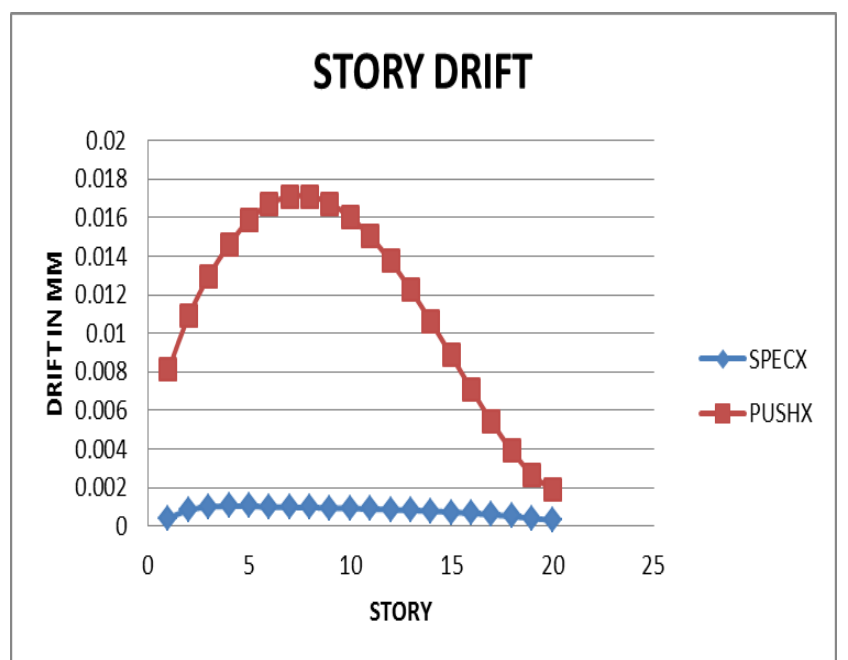

Fig 10 shows the curve of story shear of removal of middle column in shorter direction.

\section{Story Shear}

Table 7 : story shear of removal of middle column in

\begin{tabular}{|l|l|l|}
\hline \multicolumn{3}{|c}{ shorter direction } \\
\hline 20 & 138.47 & 312.78 \\
\hline 19 & 284.37 & 659.63 \\
\hline 18 & 402.64 & 971.05 \\
\hline 17 & 494.08 & 1248.95 \\
\hline 16 & 564.11 & 1495.24 \\
\hline 15 & 619.82 & 1711.83 \\
\hline 14 & 666.55 & 1900.62 \\
\hline 13 & 606.61 & 2063.52 \\
\hline 12 & 741.96 & 2202.44 \\
\hline 11 & 774.16 & 2319.29 \\
\hline 10 & 806.1 & 2415.97 \\
\hline 9 & 839.59 & 2492.41 \\
\hline 8 & 874.92 & 2556.49 \\
\hline 7 & 912.01 & 2604.14 \\
\hline 6 & 951.41 & 2639.14 \\
\hline 5 & 993.67 & 2663.58 \\
\hline 4 & 1036.26 & 2679.36 \\
\hline 3 & 1073.15 & 2688.33 \\
\hline 2 & 1097.51 & 2692.41 \\
\hline 1 & 1106.72 & 2693.5 \\
\hline
\end{tabular}




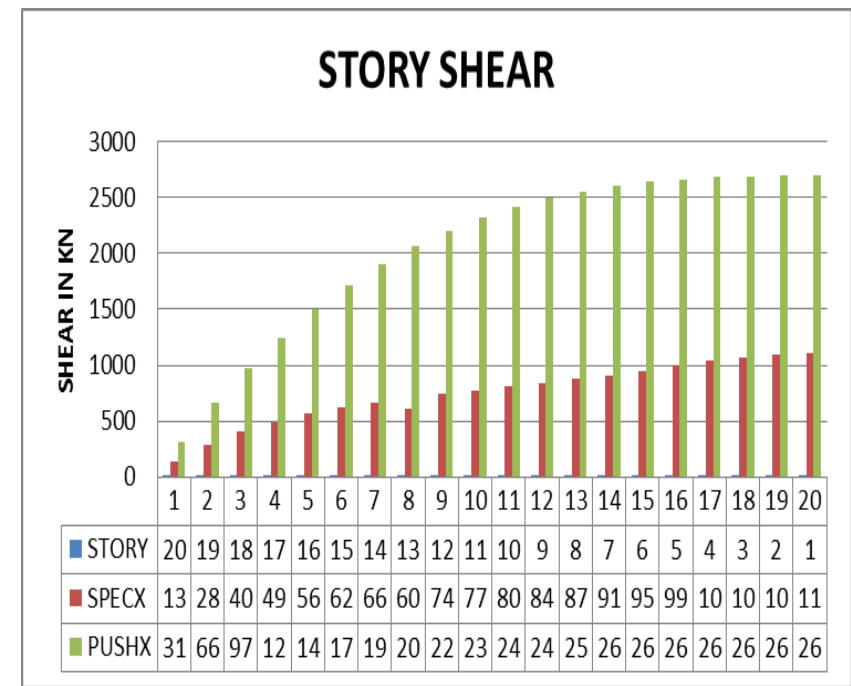

Fig 11 shows the curve of story shear of removal of middle column in shorter direction.

\subsection{Bending Moments}

\subsubsection{Moment in Bare Frame Model}

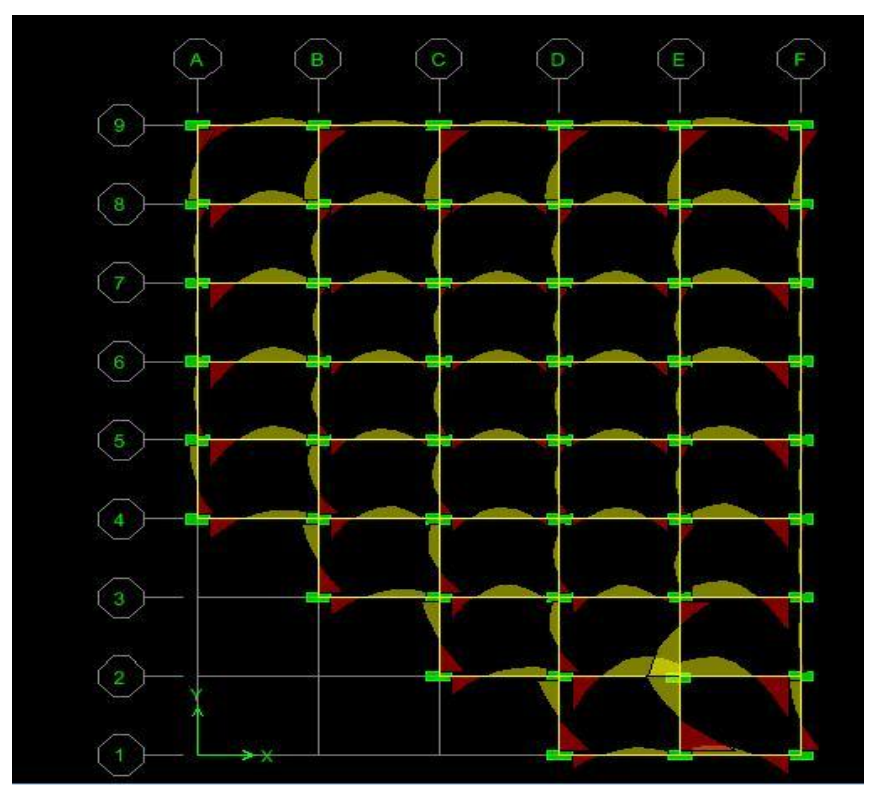

Fig 12 shows the moments of bare frame model

\subsubsection{Moment in Removal of Corner Column in}

\section{Shorter Direction}

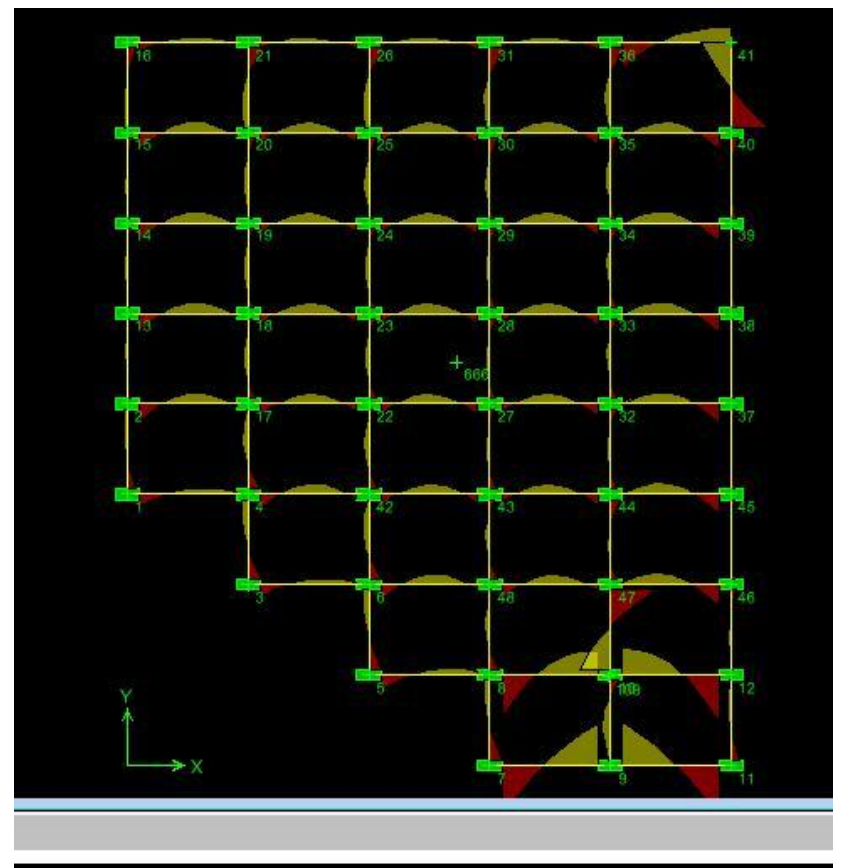

Fig 13 shows the moments of corner column removal model

\subsubsection{Moment in Removal of Middle Column in}

\section{Shorter Direction}

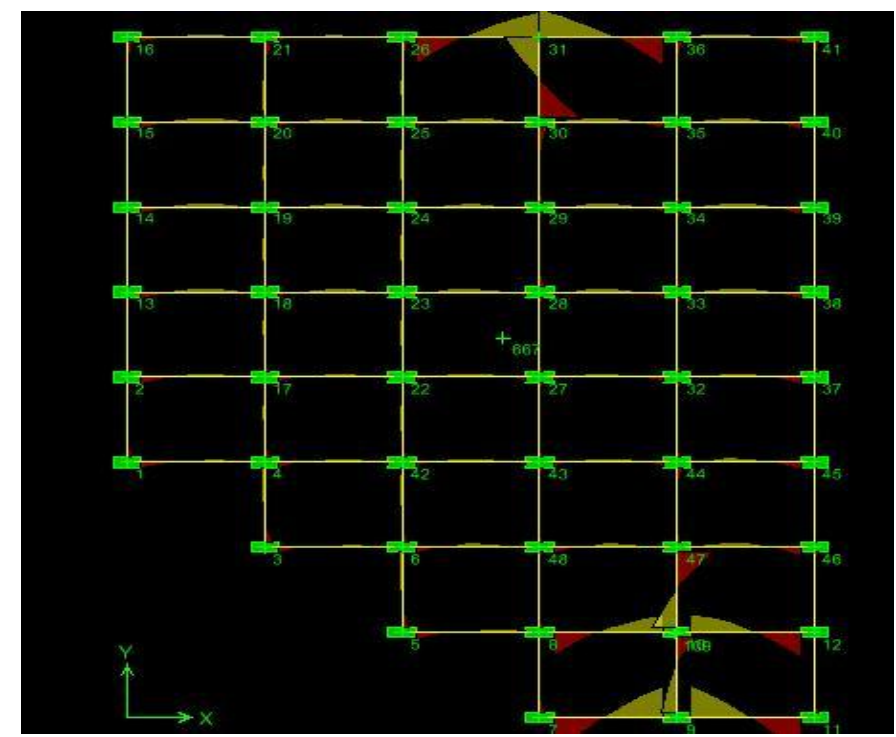

Fig 14 shows the moments of middle column removal model 


\subsection{Push Over Curves for the Model Considered for} this Study in X \& Y Directions

\subsubsection{Push Over Curves of Bare Frame Model}

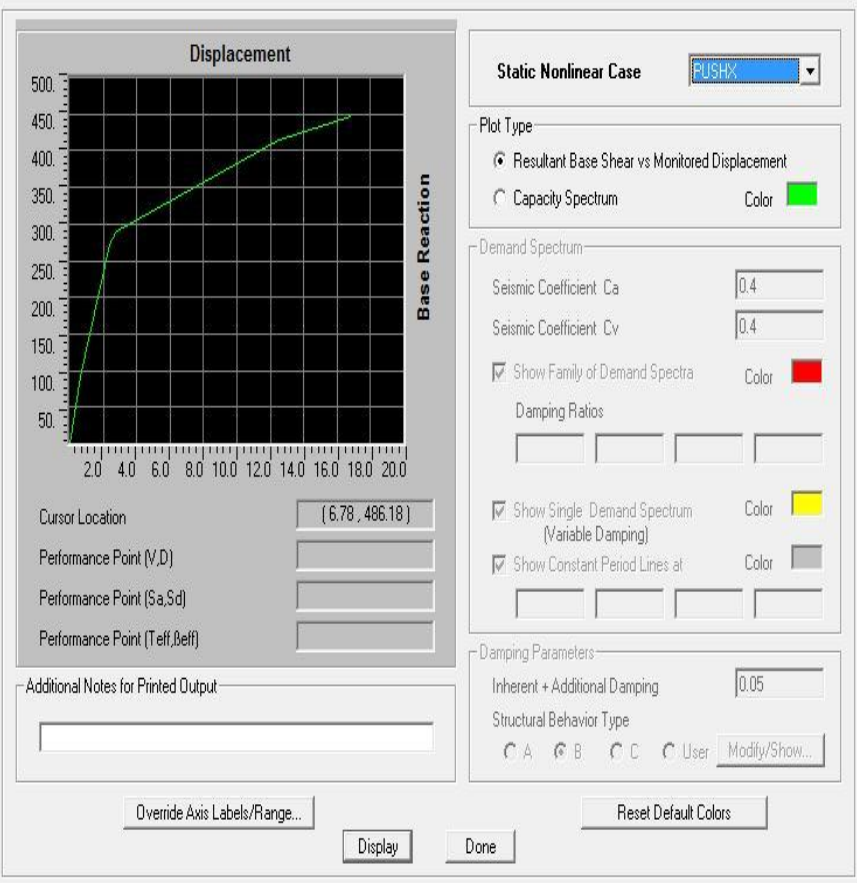

Fig 15 shows the push over curve of bare frame model in "X" direction.

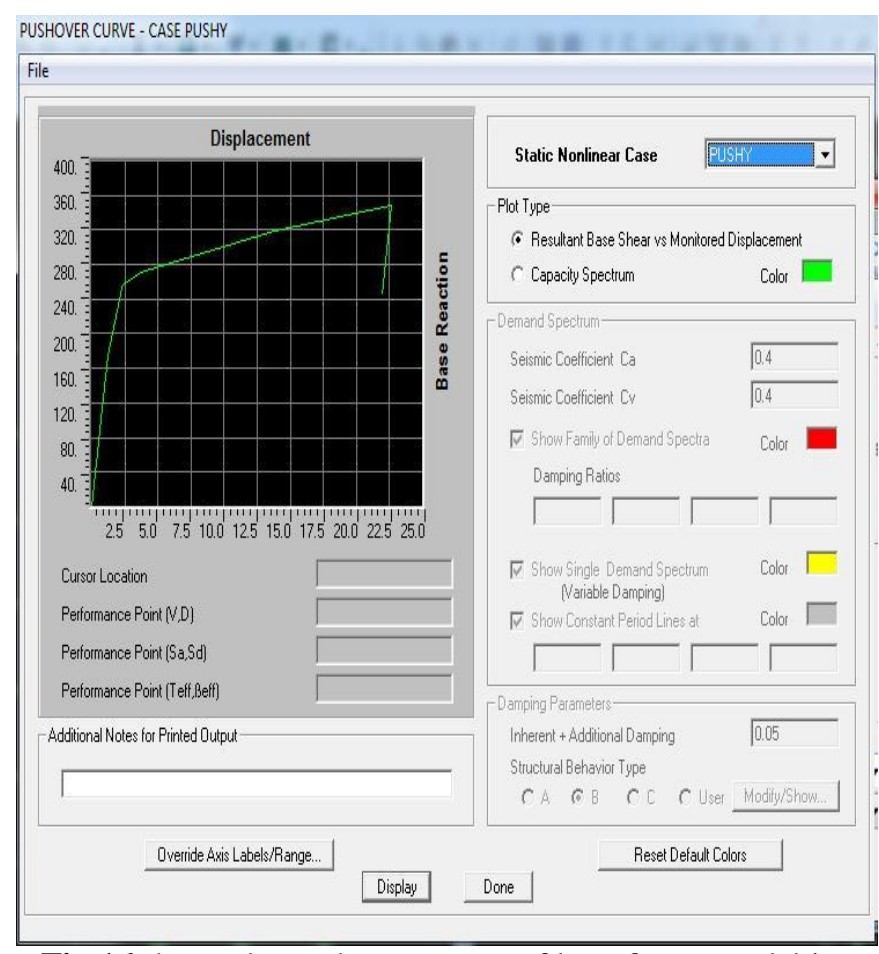

Fig 16 shows the push over curve of bare frame model in "Y" direction.

\subsubsection{Push Over Curves of Removal of Corner}

\section{Column in Shorter Direction}

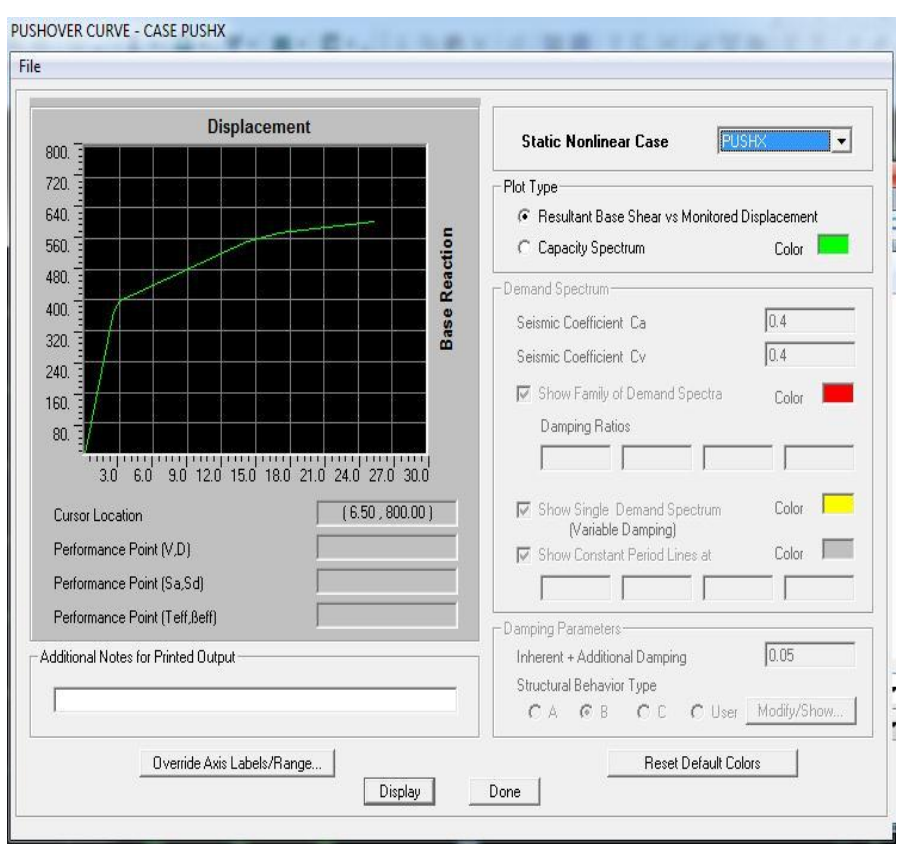

Fig 17 shows the push over curve of removal of corner column in " $\mathrm{X}$ " direction.

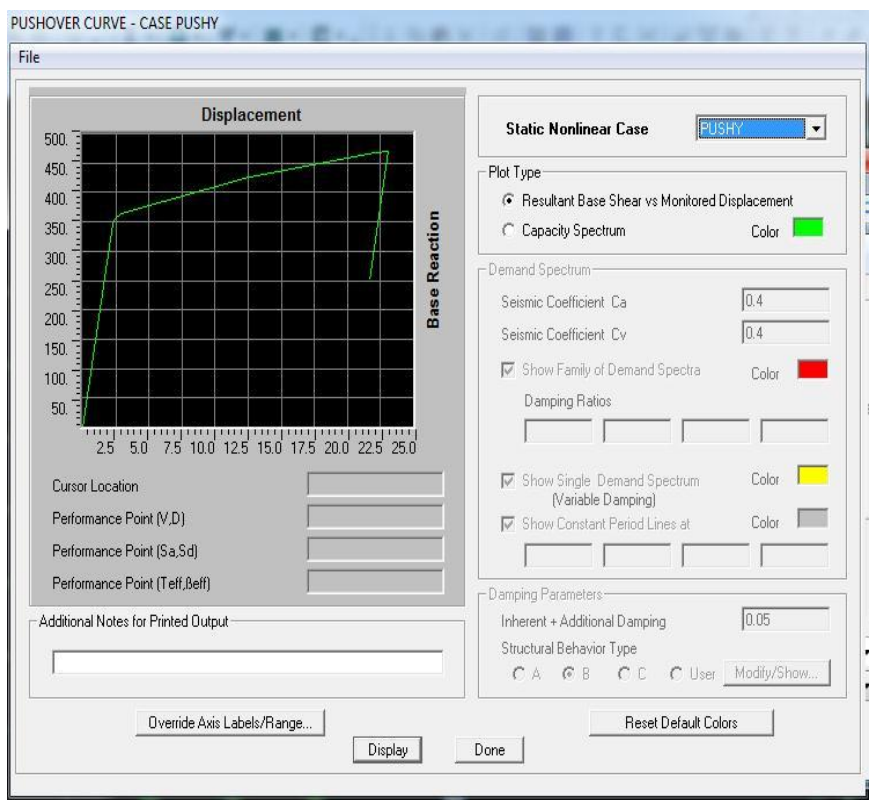

Fig 18 shows the push over curve of removal of corner column in "Y" direction. 


\subsubsection{Push Over Curves of Removal of Corner}

\section{Column in Shorter Direction}

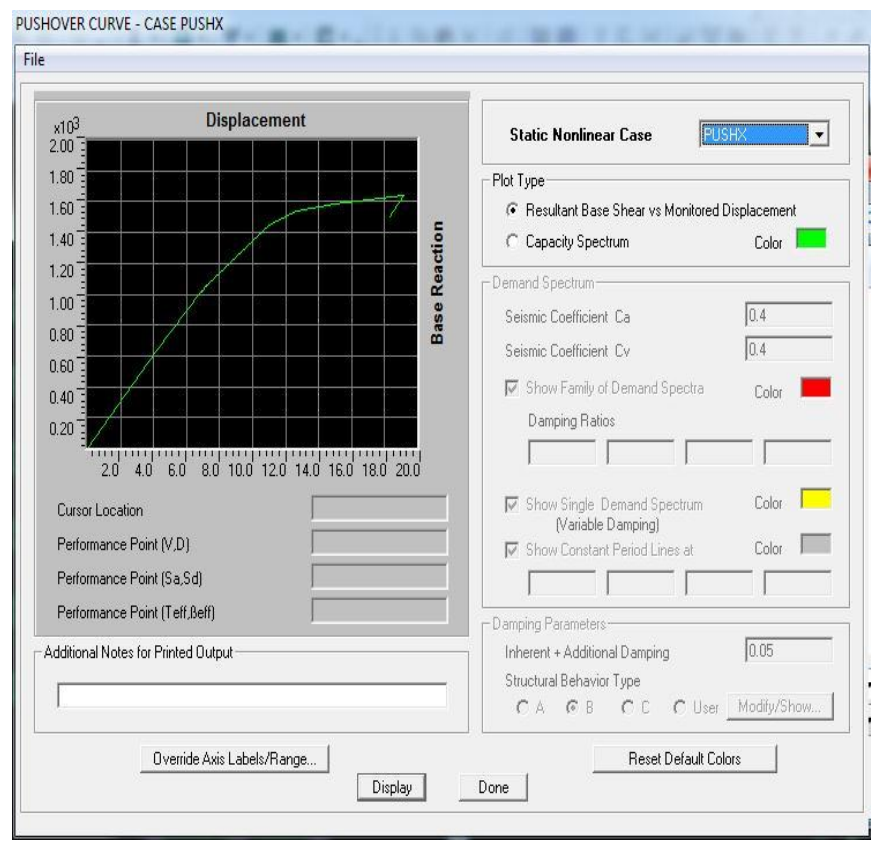

Fig 19 shows the push over curve of removal of middle column in " $\mathrm{X}$ " direction.

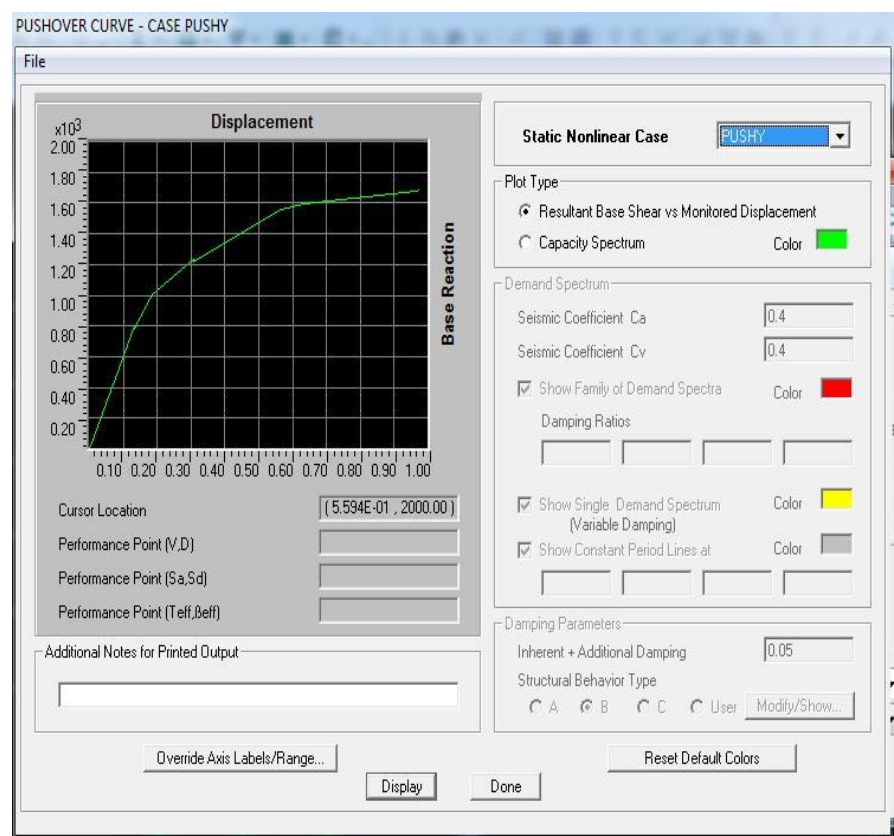

Fig 20 shows the push over curve of removal of middle column in "Y" direction.

\section{CONCLUSION}

- $\quad$ Results obtained such as story drift \& story shear from both linear dynamic \& non linear static analysis from table 2 to table $7 \&$ fig 6 to fig 11 , it is seen that the results from non linear static analysis are much more greater than linear dynamic analysis.

- The value of story drift increases as story height increases upto certain story and then decreases.
- The bending moments obtained after the analysis are as shown from fig 12 to fig 14. It is seen that the moments at the place where columns have been removed are much more when compared to other joints.

- The progressive collapse mechanism will be studied for the considered building model.

- The capacity curve or push over curve obtained by plotting the graph for displacement and base shear and as shown from fig 15to fig 20 to both longitudinal $\mathrm{X}$ to transverse Y direction

\section{REFERENCES}

[1] Mohammed Gh \& Farshad Hashemi Rezwani (15WCEE, 2012) "Seismic progressive collapse analysis of concentrically braced frames through incremental dynamic analysis".

[2] Rakshith K G \& Radhakrishna "Progressive Collapse Analysis of Reinforced Concrete Framed Structure"

[3] Satish Rathod, Yogeendra R.\& Holebagilu (2013) "Progressive Collapse Analysis of an RC Structures resting on Sloping Ground"

[4] IS 456:2000, "Code of practice for plain and reinforced concrete"( Fourth Revision ).

[5] IS 1893:1987. "Criteria for earthquake resistant design of structures.

[6] Preeti K. Morey \& Prof S.R.Satone "Progressive Collapse Analysis Of Building"

[7] Halil Sezen \& Kevin A. Giriunas "Progressive Collapse Analysis of an Existing Building"

[8] Leo shin'Proggressive Collapse Failure Mechanism”( November 1, 2010)

\section{BIOGRAPHIES}

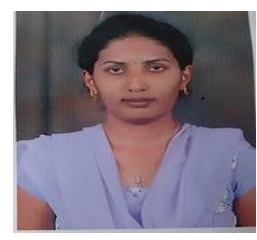

Shilpa Shree G C, Post graduate student, Ghousia college of engineering, Ramanagaram562159,Karnataka, India

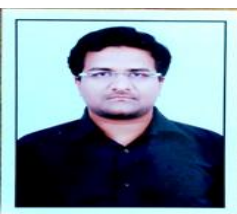

Syed Ahamed Raza, Assistant Professor, Ghousia college of engineering, Ramanagaram562159,Karnataka, India. He completed his bachelor's degree from STJIT, Ranebennur in the year 2011 master of engg from GEC, Haveri in the year 2013. He has got teaching experience of 2 years. His areas of interest are earthquake resistant structures and structural designing. 